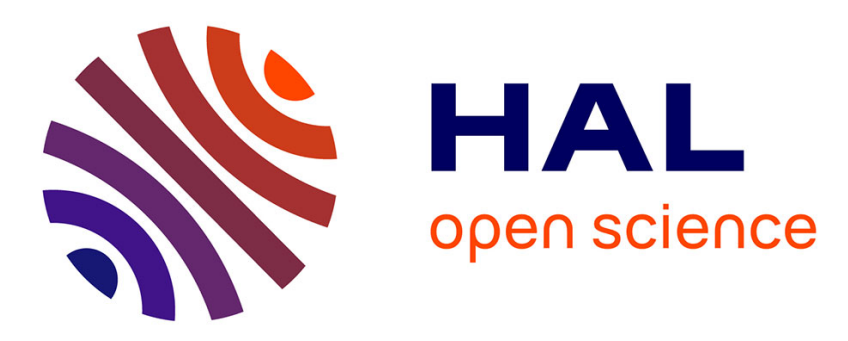

\title{
Behavioural evidence of magnetoreception in dolphins: detection of experimental magnetic fields
}

Dorothee Kremers, Juliana López Marulanda, Martine Hausberger, Alban Lemasson

\section{- To cite this version:}

Dorothee Kremers, Juliana López Marulanda, Martine Hausberger, Alban Lemasson. Behavioural evidence of magnetoreception in dolphins: detection of experimental magnetic fields. The Science of Nature Naturwissenschaften, 2014, 101 (11), pp.907-911. 10.1007/s00114-014-1231-x . hal-01134557

\section{HAL Id: hal-01134557 https://hal.science/hal-01134557}

Submitted on 23 Mar 2015

HAL is a multi-disciplinary open access archive for the deposit and dissemination of scientific research documents, whether they are published or not. The documents may come from teaching and research institutions in France or abroad, or from public or private research centers.
L'archive ouverte pluridisciplinaire HAL, est destinée au dépôt et à la diffusion de documents scientifiques de niveau recherche, publiés ou non, émanant des établissements d'enseignement et de recherche français ou étrangers, des laboratoires publics ou privés. 
Behavioural evidence of magnetoreception in dolphins: Detection of experimental $\underline{\text { magnetic fields }}$

Dorothee Kremers ${ }^{1}$, Juliana López Marulanda ${ }^{1}$, Martine Hausberger ${ }^{1}$, Alban Lemasson $^{1,2}$

${ }^{1}$ Université de Rennes 1, Laboratoire d'Éthologie Animale et Humaine - UMR CNRS 6552, Station Biologique, Paimpont, France

${ }^{2}$ Institut Universitaire de France, Paris, France

Correspondence:

Alban Lemasson

EthoS UMR6552

Station Biologique 35380 Paimpont, France

alban.lemasson@univ-rennes1.fr 


\section{Abstract}

Magnetoreception, meaning the perception of magnetic fields, is supposed to play an important role for orientation/navigation in some terrestrial and aquatic species. Although some spatial observations of free-ranging cetaceans' migration routes and stranding sites led to the assumption that cetaceans may be sensitive to the geomagnetic field, experimental evidence is lacking. Here we tested the spontaneous response of six captive bottlenose dolphins to the presentation of two magnetized and demagnetized controlled devices while they were swimming freely. Dolphins approached the device with shorter latency when it contained a strongly magnetized neodymium block compared to a control demagnetized block that was identical in form and density and therefore undistinguishable with echolocation. We conclude that dolphins are able to discriminate the two stimuli on the basis of their magnetic properties, a prerequisite for magnetoreception-based navigation.

\section{Keywords:}

Sensory perception - Magnetic sense - Cetaceans 


\section{INTRODUCTION}

The geomagnetic field is a dipole field generated by the Earth's fluid outer iron core (Wiltschko \& Wiltschko 1995) providing a consistent source of directional information (Winklhofer 2010). Different taxa can detect this magnetic field, although primary magnetoreceptors have not yet been unequivocally identified (Lohmann \& Johnson 2000; Winklhofer 2010). Several species use geomagnetic cues for orientation during navigation and migration (Wiltschko \& Wiltschko 1995). Some mammalian species respond to the geomagnetic field by spontaneously orientating their body with respect to magnetic field lines (Begall et al. 2008; Červený et al. 2011; Wang et al. 2007). Other mammals, notably rodents, build their nests by referring to the magnetic field (Kimchi \& Terkel 2001; Marhold et al. 1997) or use a magnetic compass to navigate (Holland et al. 2006).

Geomagnetic information is not only available on land, but also at sea, providing potential navigational cues (Walker \& Dennis 2005). Observations of free-ranging cetaceans show some evidence of magnetoreception-based navigation. Fin whale migration routes are correlated with low geomagnetic intensity (Walker et al. 1992). Furthermore, offshore cetaceans' live strandings seem to occur where valleys in the geomagnetic field cross the coast (Kirschvink et al. 1986; Klinowska 1985). However, experimental evidence for magnetoreception in cetaceans is lacking. When captive bottlenose dolphins were exposed to a magnetic field (introduced into their pool by an induction coil; magnetic field strength unknown) they did not show any spontaneous response (Bauer et al. 1985). Even during a series of conditioning experiments using twochoice discrimination and go/no go designs (magnetic field strength: $37 \mu \mathrm{T}$ ) the dolphins did not show any indication of a magnetic discrimination (Bauer et al. 1985). However, Bauer et al. (1985) admitted that "experiments that constrain the subject in time and place 
may be putting significant limits on appropriate orientation". Therefore we conducted an experiment that neither confined the dolphins spatially to one position as for example during a go/no go experiment nor demanded a direct response as it is the case in conditioning experiments, but rather observed their spontaneous reaction towards magnetized and demagnetized devices.

\section{METHODS}

\subsection{Study subjects and housing conditions}

In January/February 2013, we studied six captive-born bottlenose dolphins (Tursiops truncatus; four males: aged 5, 8, 14, and 29 years; two females: aged 5 and 12 years) in the delphinarium of Planète Sauvage (Port-Saint-Père, France). Overall, this outdoor facility consists of four pools, covering $2000 \mathrm{~m}^{2}$ water surface and containing 7,500,000 I salt water. During the entire experiment, the animals were free to move in and out the pool where the experimental device was installed (details: ESM), meaning that all six individuals were tested simultaneously while all group members were free to interact at any time with the device during a given experimental session.

\subsection{Data collection}

We used a neodymium block $(10 \times 10 \times 1.5 \mathrm{~cm})$ with a magnetic field strength of $1.2 \mathrm{~T}$ (Ingeniería Magnética Aplicada, S.L., Barcelona, Spain; ESM Figure 1) that was placed in an opaque plastic barrel $(20 \times 26 \mathrm{~cm})$. During an experimental session, the barrel hung in the water at a depth of $50 \mathrm{~cm}, 40 \mathrm{~cm}$ away from the pool wall (details: ESM). Because the barrel was perforated, the magnet inside was in contact with the pool water. At the end of a session, the device was removed from the pool. The magnet remained at the same position in the barrel during all the experiment, so that magnetic field direction never 
changed. As control stimulus we used the exact same (size/density) but demagnetized neodymium block. During an experimental session, only one device was used, containing either the magnetized or the demagnetized neodymium block, and was installed by a person blind to the content of the barrel.

Before the experiment started, we conducted 51 sessions with an empty barrel to habituate the dolphins. Thereafter, 30 sessions with the magnetized block and 30 sessions with the demagnetized block were done on 13 consecutive days, presenting the two stimuli in a randomized order (1-6 experimental sessions per day). An experimental session started at the moment the barrel was placed in the water (experimenter left) and lasted 15 minutes during which the individual responses of the six dolphins were filmed by a video camera (Sony HDR-XR155) on a tripod behind the device. Sessions continued no matter if some dolphins stayed or swam out of the pool.

Later, the videos were analysed by an observer who was able to identify the dolphins but was blind to the content of the barrel visible in the video. The observation followed a continuous and simultaneous individual sampling of the six dolphins (sampling all occurrences of some previously defined behaviours), thus different behaviours that occurred during the 15 minutes within a range of $1.5 \mathrm{~m}$ around the barrel, defined as the experimental area, were measured or counted for each individual dolphin (even if several individuals were present at the same time): latency for the first approach (i.e., entering the experimental area), proximity duration (i.e., time spent within the experimental area), latencies for the first rostrum contact and the first body contact (i.e., contact with another part of the body), number and duration of rostrum and body contacts. If an individual did not approach or touch the device during a session, the session's total duration (900 sec) was used for statistical analysis on latencies. As the dolphins were not tested with 
individuals isolated and as dolphins were free to approach or not, the number of times a given dolphin was close to the barrel differed between individuals.

\subsection{Data analysis}

Due to very strong sun reflections from the water surface, one magnet session and five control sessions had to be removed from further analysis, because visibility did not allow for dolphin identification. Statistical analyses were run using $\mathrm{R}$ software (version 2.15.0). We compared all variables (approach latency, proximity duration, latencies for first rostrum and body contact, number and duration of rostrum and body contacts) between magnet and control sessions with Wilcoxon signed-rank tests using the mean values for each individual. In the text, values present meanıSE.

\section{RESULTS}

Although the six tested dolphins showed some individual differences in their responses towards the magnetized and the demagnetized stimulus (Table 1), we found that the individuals behaved overall in the same way. On the one hand most behaviour did not differ between sessions using the magnet and sessions using the control. Dolphins spent similar durations in the presence of both devices (magnet: $26.3 \pm 5.2 \mathrm{sec}$; control: 26.6 $\pm 5.0 \mathrm{sec} ; \mathrm{p}=0.5625, \mathrm{~V}=14$ ). The latencies for the first contact (rostrum contacts: magnet and control: $11.6 \pm 0.4 \mathrm{~min} ; \mathrm{p}=1, \mathrm{~V}=11$; body contacts: magnet: $14.0 \pm 0.2 \mathrm{~min}$; control: $13.5 \pm 0.3 \mathrm{~min} ; \mathrm{p}=0.1056, \mathrm{~V}=1$ ), number of contacts (rostrum contacts: magnet: 2.4 \pm 0.5 ; control: $3.4 \pm 0.8 ; \mathrm{p}=0.2188, \mathrm{~V}=17$; body contacts: magnet and control: $0.2 \pm 0.1$; $\mathrm{p}=0.7874, \mathrm{~V}=9$ ), and the duration of contacts (rostrum contacts: magnet: $2.9 \pm 0.6 \mathrm{sec}$; control: $3.8 \pm 0.9 \mathrm{sec} ; \mathrm{p}=0.3125, \mathrm{~V}=16$; body contacts: magnet: $0.4 \pm 0.1 \mathrm{sec}$; control: $0.3 \pm 0.1$ sec; $p=1, V=7$ ) did not differ statistically. One behaviour, however, differed 
between sessions using the magnet and sessions using the control: Dolphins approached the magnetized device with significantly shorter latency than the control device (magnet: 5.7 $\pm 0.5 \mathrm{~min}$; control: $6.2 \pm 0.5 \mathrm{~min} ; \mathrm{p}=0.0313, \mathrm{~V}=21$; Figure 1).

\section{DISCUSSION}

The responses of six captive bottlenose dolphins towards visually identical devices containing either a magnetized or a demagnetized neodymium block suggest that this species is capable of perceiving magnetic fields. The dolphins approached the device with shorter latency when it contained the magnetized neodymium block compared to the control that was identical in form and density, thus they discriminated between the two stimuli. To do so already at a distance of more than $1.5 \mathrm{~m}$ implies that dolphins' perceptual abilities must be very sensitive. The fact that all other behaviours did not differ between magnetized and control stimulus may reflect that magnetic field are neither particularly attractive nor repulsive to dolphins. This is, to our knowledge, the first experimentally obtained behavioural evidence for a sensitivity to magnetic stimuli in cetaceans. However, we acknowledge that, although our findings suggest that dolphins are magnetosensitive, the fact that not all behaviours differed between magnetized and control stimulus indicate the importance of further studies to yield a more precise and conclusive result.

That dolphins can sense magnetic fields was already previously suggested by Stafne \& Manger (2004) who observed that captive bottlenose dolphins in the northern hemisphere swim predominantly in counter clockwise direction, while dolphins in the southern hemisphere swim predominantly in clockwise direction, although they could not finally conclude what the reason for this behaviour was. There are not many studies testing for magnetoreception in dolphins. Kuznetsov (1999; only abstract available) 
reported that dolphins' vegetative characteristics such as electrocardiogram, galvanic skin responses, and respiration responded to changes in the magnetic field, interpreting this as "a high sensitivity of the dolphin to changes in the permanent magnetic field (a 'magnetic sense')". However, as details of this study are unknown it is difficult to evaluate.

One reason why previous experiments failed to detect a behavioural response of the dolphins toward magnetized stimuli might be the magnetic field strength. The magnet used in this study (details: ESM) created a magnetic field with a strength of approximately $0.051-0.240 \mathrm{~T}$ at a distance of $2-5 \mathrm{~cm}$ from the magnet. This means, when touching the barrel the magnetic field was roughly $1000-6000$ times stronger than the magnetic field used in the conditioning experiments of Bauer et al. (1985).

In view of the fact that the geomagnetic field is on average $4.5 \mu \mathrm{T}$ strong (Wiltschko \& Wiltschko 1995) it seems questionable whether or not dolphins' sensitivity is high enough to perceive and use geomagnetic cues for navigation. However, we did not test dolphins' perception threshold and there are several observations that found a correlation between cetaceans' occurrence and geomagnetic characteristics (Kirschvink et al. 1986; Klinowska 1985; Walker et al. 1992). Further studies are needed to address the importance of magnetic field intensity and direction on the behaviour of dolphins.

One possible mechanism to perceive magnetic fields is the presence of ferromagnetic particles, such as magnetite, in the organism's body. These miniature magnets align themselves in the magnetic field and seem to transmit this information through a connection with the central nervous system (Wiltschko \& Wiltschko 1995), although further studies are also needed to really understand this process. However, a magnetite-based system is the only one yet proposed for cetaceans (Walker et al. 1992). Magnetite has indeed been found in the dura mater of dolphins (Bauer et al. 1985; Zoeger 
et al. 1981), although this finding alone does not provide sufficient evidence for magnetitebased magnetoreception. Regardless the mechanism, cetaceans may have inherited this sensory ability from their ancestors because some of the closely related artiodactyls (Thewissen et al. 2009) are also magnetosensitive (Begall et al. 2008).

Our results provide new, experimentally obtained evidence that this phylogenetic group should be added to the list of magnetosensitive species, broadening the evolutionary view on magnetoreception.

\section{ACKNOWLEDGEMENTS}

We thank Planète Sauvage and the dolphin trainers for their cooperation, as well as Martin Böye, Françoise Joubaud and Maxime Hervé for their assistance. This study was funded by A.N.R. (grant ORILANG), I.U.F, and A.N.R.T. (grant CIFRE).

\section{DECLARATION}

The experiments described in this paper comply with the current laws of the country in which they were performed. The authors declare that they have no conflict of interest. 


\section{REFERENCES}

Bauer GB, Fuller M, Perry A, Dunn JR, Zoeger J (1985) Magnetoreception and biomineralization of magnetite in cetaceans. In: Kirschvink JL, Jones DS, MacFadden BJ (eds) Magnetite biomineralization and magnetoreception in organisms: A new biomagnetism. Plenum Press, New York, pp 489-507

Begall S, Cerveny J, Neef J, Vojtech O, Burda H (2008) Magnetic alignment in grazing and resting cattle and deer. Proc Natl Acad Sci USA 105:13451-13455

Červený J, Begall S, Koubek P, Nováková P, Burda H (2011) Directional preference may enhance hunting accuracy in foraging foxes. Biol Lett doi:10.1098/rsbl.2010.1145

Holland RA, Thorup K, Vonhof M, Cochran WW, Wikelski M (2006) Bat orientation using Earth's magnetic field. Nature 444:653-702

Kimchi T, Terkel J (2001) Magnetic compass orientation in the blind mole rat Spalax ehrenbergi. J Exp Biol 204:751-758

Kirschvink JL, Dizon AE, Westphal JA (1986) Evidence from strandings for geomagnetic sensitivity in cetaceans. J Exp Biol 120:1-24

Klinowska L (1985) Cetacean live stranding sites relate to geomagnetic topography. Aquatic Mammals 1:27-32

Kuznetsov VB. (1999) Vegetative reactions of dolphins to a change in the permanent magnetic field. Biofizika 44:496-502 [article in Russian, only abstract available in English]

Lohmann KJ, Johnson S (2000) The neurobiology of magnetoreception in vertebrate animals. TINS 23:153-159

Marhold S, Wiltschko W, Burda H (1997) A magnetic polarity compass for direction finding in a subterranean mammal. Naturwissenschaften 84:421-423

Stafne GM, Manger PR (2004) Predominance of clockwise swimming during rest in southern hemisphere dolphins. Physiol Behav 82:919-926

Thewissen JGM, Cooper LN, George JC, Bajpai S (2009) From land to water: the origin of whales, dolphins, and porpoises. Evo. Edu. Outreach 2:272-288

Walker MM, Dennis TE (2005) Role of the magnetic sense in the distribution and abundance of marine animals. Marine Ecology Progress Series 287: 295-307

Walker MM, Kirschvink JL, Ahmed G, Diction AE (1992) Evidence that fin whales respond to the geomagnetic field during migration. J Exp Biol 171:67-78 
Wang Y, Pan Y, Parsons S, Walker MM, Zhang S (2007) Bats respond to polarity of a magnetic field. Proc Roy Soc B 274:2901-2905

Wiltschko R, Wiltschko W (1995) Magnetic orientation in animals. Springer, Berlin Heidelberg New York

Winklhofer M (2010) Magnetoreception. J R Soc Interface 7:S131-S134

Zoeger J, Dunn JR, Fuller M (1981) Magnetic material in the head of the common Pacific dolphin. Science 213:892-894 


\section{TABLES}

Tab. 1 Mean $\pm S E$ values and ranges for each variable measured (minimum-maximum) for each individual dolphin (sex/age given in parenthesis after the name) during magnet $(\mathrm{N}=29)$ and control $(\mathrm{N}=25)$ sessions. Interpretation of latency variables: $0.0 \mathrm{~min}=$ dolphin approached/touched experimental device as soon as it was placed in the water; $15 \mathrm{~min}=$ dolphin never approached/touched experimental device during a session.

\begin{tabular}{|c|c|c|c|c|c|c|c|}
\hline Variable & Stimulus & $\begin{array}{l}\text { Amtan } \\
(0,12)\end{array}$ & $\begin{array}{c}\text { Cecil } \\
(0,29)\end{array}$ & $\begin{array}{c}\text { Kite } \\
(0,8)\end{array}$ & $\begin{array}{l}\text { Parel } \\
(\uparrow, 5)\end{array}$ & $\begin{array}{c}\text { Peos } \\
(0,14)\end{array}$ & $\begin{array}{l}\text { Spat } \\
(0,5)\end{array}$ \\
\hline \multirow{2}{*}{$\begin{array}{c}\text { latency for } \\
1^{\text {st }} \\
\text { approach } \\
\text { [min] }\end{array}$} & magnet & $\begin{array}{c}5.7 \pm 1.1 \\
0.0-15\end{array}$ & $\begin{array}{c}2.5 \pm 0.7 \\
0.0-15\end{array}$ & $\begin{array}{c}11.9 \pm 1.0 \\
0.05-15\end{array}$ & $\begin{array}{c}3.8 \pm 1.0 \\
0.0-15\end{array}$ & $\begin{array}{l}5.0 \pm 0.9 \\
0.03-15\end{array}$ & $\begin{array}{l}5.6 \pm 1.0 \\
0.0-15\end{array}$ \\
\hline & control & $\begin{array}{c}7.0 \pm 1.2 \\
0.0-15 \\
\end{array}$ & $\begin{array}{l}2.9 \pm 0.7 \\
0.1-14.0\end{array}$ & $\begin{array}{c}12.0 \pm 1.0 \\
1.2-15 \\
\end{array}$ & $\begin{array}{c}3.9 \pm 1.1 \\
0.0-15 \\
\end{array}$ & $\begin{array}{c}5.5 \pm 1.0 \\
0.0-15\end{array}$ & $\begin{array}{l}5.9 \pm 1.2 \\
0.03-15 \\
\end{array}$ \\
\hline \multirow{2}{*}{$\begin{array}{c}\text { proximity } \\
\text { duration } \\
\text { [sec] }\end{array}$} & magnet & $\begin{array}{c}30.6 \pm 7.9 \\
0-193\end{array}$ & $\begin{array}{c}25.5 \pm 3.2 \\
0-70\end{array}$ & $\begin{array}{c}1.6 \pm 0.7 \\
0-18\end{array}$ & $\begin{array}{c}49.3 \pm 18.2 \\
0-484\end{array}$ & $\begin{array}{c}18.9 \pm 7.0 \\
0-183\end{array}$ & $\begin{array}{c}32.0 \pm 21.9 \\
0-653\end{array}$ \\
\hline & control & $\begin{array}{c}34.9 \pm 11.5 \\
0-216\end{array}$ & $\begin{array}{c}15.8 \pm 2.5 \\
2-43\end{array}$ & $\begin{array}{c}2.1 \pm 0.9 \\
0-19\end{array}$ & $\begin{array}{c}52.4 \pm 15.4 \\
0-288\end{array}$ & $\begin{array}{c}22.9 \pm 9.3 \\
0-226\end{array}$ & $\begin{array}{c}31.8 \pm 19.5 \\
0-505\end{array}$ \\
\hline \multirow{2}{*}{$\begin{array}{l}\text { latency for } \\
1^{\text {st }} \text { rostrum } \\
\text { contact } \\
\text { [min] }\end{array}$} & magnet & $\begin{array}{c}9.0 \pm 1.2 \\
0.0-15\end{array}$ & $\begin{array}{c}13.4 \pm 0.7 \\
0.8-15\end{array}$ & $\begin{array}{c}15.0 \pm 0.0 \\
15\end{array}$ & $\begin{array}{c}7.6 \pm 1.3 \\
0.0-15\end{array}$ & $\begin{array}{c}11.9 \pm 1.0 \\
0.5-15\end{array}$ & $\begin{array}{c}13.0 \pm 0.8 \\
0.3-15\end{array}$ \\
\hline & control & $\begin{array}{l}9.9 \pm 1.2 \\
0.02-15\end{array}$ & $\begin{array}{c}13.3 \pm 0.7 \\
0.8-15\end{array}$ & $\begin{array}{c}14.4 \pm 0.5 \\
1.1-15\end{array}$ & $\begin{array}{l}7.8 \pm 1.3 \\
0.03-15\end{array}$ & $\begin{array}{c}12.5 \pm 0.9 \\
0.3-15\end{array}$ & $\begin{array}{c}11.8 \pm 1.1 \\
0.03-15\end{array}$ \\
\hline \multirow{2}{*}{$\begin{array}{l}\text { number of } \\
\text { rostrum } \\
\text { contacts }\end{array}$} & magnet & $\begin{array}{c}4.2 \pm 1.6 \\
0-44\end{array}$ & $\begin{array}{c}1.3 \pm 0.6 \\
0-13\end{array}$ & $\begin{array}{l}0 \\
0\end{array}$ & $\begin{array}{c}6.0 \pm 1.9 \\
0-38\end{array}$ & $\begin{array}{c}1.8 \pm 1.1 \\
0-30\end{array}$ & $\begin{array}{c}0.9 \pm 0.5 \\
0-12\end{array}$ \\
\hline & control & $\begin{array}{c}4.7 \pm 1.6 \\
0-28\end{array}$ & $\begin{array}{c}0.8 \pm 0.4 \\
0-9\end{array}$ & $\begin{array}{c}0.2 \pm 0.2 \\
0-6\end{array}$ & $\begin{array}{c}9.2 \pm 2.6 \\
0-39\end{array}$ & $\begin{array}{c}1.6 \pm 0.9 \\
0-20\end{array}$ & $\begin{array}{c}3.9 \pm 2.9 \\
0-74\end{array}$ \\
\hline \multirow{2}{*}{$\begin{array}{c}\text { duration of } \\
\text { rostrum } \\
\text { contacts } \\
\text { [sec] }\end{array}$} & magnet & $\begin{array}{c}5.8 \pm 2.1 \\
0-53.5\end{array}$ & $\begin{array}{c}0.8 \pm 0.3 \\
0-8\end{array}$ & $\begin{array}{l}0 \\
0\end{array}$ & $\begin{array}{c}9.1 \pm 2.7 \\
0-55.5\end{array}$ & $\begin{array}{c}1.5 \pm 1.0 \\
0-28.5\end{array}$ & $\begin{array}{c}0.7 \pm 0.4 \\
0-9\end{array}$ \\
\hline & control & $\begin{array}{c}5.1 \pm 1.9 \\
0-40.5\end{array}$ & $\begin{array}{c}0.6 \pm 0.3 \\
0-6.5 \\
\end{array}$ & $\begin{array}{c}0.5 \pm 0.5 \\
0-13.5 \\
\end{array}$ & $\begin{array}{c}11.6 \pm 3.7 \\
0-64\end{array}$ & $\begin{array}{c}1.6 \pm 1.0 \\
0-24\end{array}$ & $\begin{array}{c}3.7 \pm 2.7 \\
0-68\end{array}$ \\
\hline \multirow{2}{*}{$\begin{array}{c}\text { latency for } \\
1^{s t} \text { body } \\
\text { contact } \\
\text { [min] }\end{array}$} & magnet & $\begin{array}{c}15.0 \pm 0.0 \\
15\end{array}$ & $\begin{array}{c}14.9 \pm 0.1 \\
11.4-15 \\
\end{array}$ & $\begin{array}{c}15.0 \pm 0.0 \\
15\end{array}$ & $\begin{array}{c}12.7 \pm 0.9 \\
0.9-15\end{array}$ & $\begin{array}{c}14.5 \pm 0.5 \\
0.1-15\end{array}$ & $\begin{array}{c}12.1 \pm 0.9 \\
0.7-15\end{array}$ \\
\hline & control & $\begin{array}{c}15.0 \pm 0.0 \\
15\end{array}$ & $\begin{array}{c}14.6 \pm 0.1 \\
10.0-15 \\
\end{array}$ & $\begin{array}{c}14.4 \pm 0.04 \\
1.2-15 \\
\end{array}$ & $\begin{array}{c}10.7 \pm 0.1 \\
0.7-15 \\
\end{array}$ & $\begin{array}{c}14.6 \pm 0.1 \\
5.8-15 \\
\end{array}$ & $\begin{array}{c}11.9 \pm 0.3 \\
0.3-15 \\
\end{array}$ \\
\hline \multirow{2}{*}{$\begin{array}{c}\text { number of } \\
\text { body } \\
\text { contacts }\end{array}$} & magnet & $\begin{array}{l}0 \\
0\end{array}$ & $\begin{array}{c}0.03 \pm 0.03 \\
0-1\end{array}$ & $\begin{array}{l}0 \\
0\end{array}$ & $\begin{array}{c}0.7 \pm 0.3 \\
0-6\end{array}$ & $\begin{array}{c}0.1 \pm 0.1 \\
0-2\end{array}$ & $\begin{array}{c}0.7 \pm 0.2 \\
0-6\end{array}$ \\
\hline & control & $\begin{array}{l}0 \\
0\end{array}$ & $\begin{array}{c}0.2 \pm 0.1 \\
0-2\end{array}$ & $\begin{array}{c}0.04 \pm 0.04 \\
0-1\end{array}$ & $\begin{array}{c}0.4 \pm 0.1 \\
0-1\end{array}$ & $\begin{array}{c}0.1 \pm 0.1 \\
0-1\end{array}$ & $\begin{array}{c}0.7 \pm 0.3 \\
0-6\end{array}$ \\
\hline \multirow{2}{*}{$\begin{array}{c}\text { duration of } \\
\text { body } \\
\text { contacts } \\
\text { [sec] }\end{array}$} & magnet & $\begin{array}{l}0 \\
0\end{array}$ & $\begin{array}{c}0.03 \pm 0.03 \\
0-1\end{array}$ & $\begin{array}{l}0 \\
0\end{array}$ & $\begin{array}{c}1.1 \pm 0.5 \\
0-14.5\end{array}$ & $\begin{array}{c}0.1 \pm 0.1 \\
0-2\end{array}$ & $\begin{array}{c}1.2 \pm 0.6 \\
0-18.5\end{array}$ \\
\hline & control & $\begin{array}{l}0 \\
0\end{array}$ & $\begin{array}{c}0.3 \pm 0.2 \\
0-6\end{array}$ & $\begin{array}{c}0.1 \pm 0.1 \\
0-3\end{array}$ & $\begin{array}{c}0.5 \pm 0.2 \\
0-3\end{array}$ & $\begin{array}{c}0.1 \pm 0.1 \\
0-1\end{array}$ & $\begin{array}{c}0.9 \pm 0.4 \\
0-8.5\end{array}$ \\
\hline
\end{tabular}




\section{FIGURES}

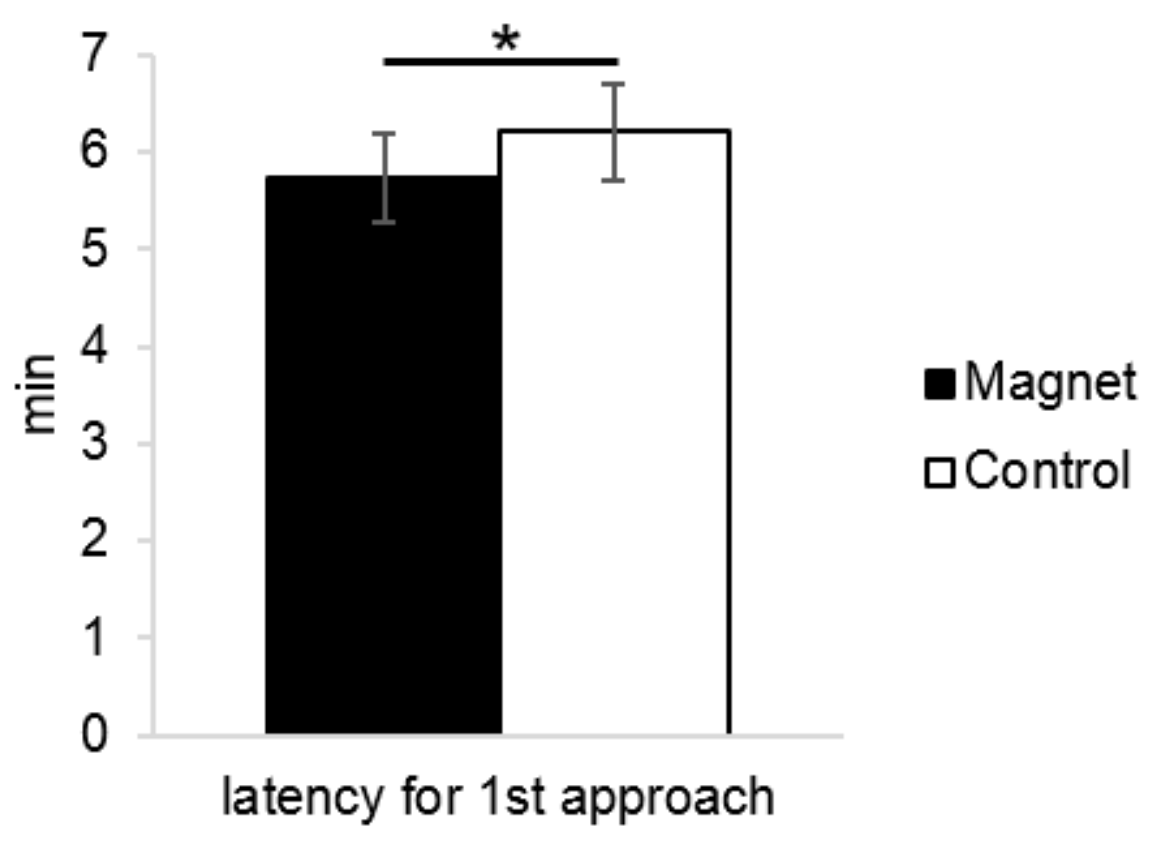

Fig. 1 Dolphins' mean \pm SE latency [min] to approach the magnetized stimulus (in black) is shorter compared to the control (in white; Wilcoxon signed-rank test; ${ }^{*} p \leq 0.05$ ). 


\section{ELECTRONIC SUPPLEMENTARY MATERIAL}

\section{Details on the methodology}

\subsection{Study subjects and housing conditions}

The six studied captive-born bottlenose dolphins were housed in the outdoor facility of the safari park Planète Sauvage (Port-Saint-Père, France). Daily routine comprised seven training/feeding sessions conducted by the dolphin trainers including medical training (e.g. acceptance of inspection and palpation of all parts of the body or being touched by medical equipment) as well as training for public shows (e.g., jump on command). During this study Planète Sauvage was closed due to winter season therefore no public shows took place at this time. Water temperature ranged from 12.5 to $15.3^{\circ} \mathrm{C}$ (mean $14.06 \pm 0.13^{\circ} \mathrm{C}$ ) and salinity from 25.0 to $26.4 \%$ (mean $25.54 \pm 0.11 \%$, achieved by mixing ground water with $26-29 \mathrm{~g}$ salt per litre). The experiment took place in a circular pool (diameter: $20 \mathrm{~m}$; depth: $4.5 \mathrm{~m}$ ) because its symmetry provided identical conditions (i.e. pool characteristics such as shape of the pool walls) at every location used to install the experimental device. Three different locations at this pool were randomly used in order to prevent from any possible influence of the location on the dolphins' behaviour.

\subsection{Data collection}

We used a neodymium block (length: $10 \mathrm{~cm}$; width: $10 \mathrm{~cm}$; height: $1.5 \mathrm{~cm}$ ) with an magnetic-field strength of 1.2 T (Ingeniería Magnética Aplicada, S.L., Barcelona, Spain). The block was placed in an opaque plastic barrel (diameter: $20 \mathrm{~cm}$; height: $26 \mathrm{~cm}$ ) which in turn was placed in the water $40 \mathrm{~cm}$ from the pool wall at a depth of $50 \mathrm{~cm}$ by hanging from a wooden plank (that was covered with neoprene to avoid injury) to which it was attached (knotted) with a cord. To allow water inflow, the barrel was perforated with 40 
small holes (diameter: $3 \mathrm{~mm}$ ) and 3 larger holes (diameter: $1 \mathrm{~cm} ; 2$ at the bottom to fix the neodymium block inside and 1 in the lid to attach the cord). Together with the neodymium block a $1 \mathrm{~kg}$ plumbum weight was fixed inside the barrel using two plastic cable ties in order to ensure a fast submergence of the device. The barrel moved slightly with the water movement but stronger when it was touched by a dolphin. At the end of a session, the whole device was removed from the pool. The block remained at the same position in the barrel during all the experiment, so that polarity never changed. As control stimulus we used the exact same (size and density) but demagnetized neodymium block (Ingeniería Magnética Aplicada, S.L., Barcelona, Spain). The demagnetization was achieved by placing the neodymium block in a coil (conducted by the manufacturer); this control block still possessed a very weak magnetic field $(<0.005 \mathrm{~T})$ leading to a magnetic field strength of less than 200-250 $\mu \mathrm{T}$ at the barrel's surface. During an experimental session, only one device was used containing either the magnetized or the demagnetized neodymium block, and was always installed by a person blind to the content of the barrel.

Although there were steel beams inside the pool walls, the distance to the magnet was more than $65 \mathrm{~cm}$ : $25 \mathrm{~cm}$ of concrete wall plus $40 \mathrm{~cm}$ distance between wall and barrel plus 2-5 cm distance between barrel and neodymium block (depending if taking the edge or the length of the square-shaped block). Therefore we consider a possible interaction between the steel beams and the magnet as limited. There was no other iron source in the pool and also the presence of iron sediment in the water (which could accumulate around the barrel containing the magnetized neodymium block, leading to a potential visual indicator of the magnetic field) can clearly be ruled out.

As the device was new to the animals, we presented it empty during 51 sessions lasting 15 minutes each without any block inside for habituation on the nine days before 
the experiment began. Then, we conducted 54 experimental sessions (29 with the magnetized stimulus; 25 with the demagnetized stimulus), presenting the two stimuli in a randomized order. Location of the device at the pool was also changed randomly between three possible positions to avoid any influence of location. Experimental sessions took place between the training/feeding sessions and lasted 15 minutes. One to 6 experimental sessions were performed per day ( $N=13$ days in total). On average, the time interval between two experimental sessions was $1 \mathrm{~h} 19 \mathrm{~min}( \pm 5 \mathrm{~min})$, the minimum time interval 30 minutes.

\subsection{Characteristics of the magnetized neodymium block}

We conducted our own measurement of the neodymium block's magnetic field with a gaussmeter (Bell 640 Incremental Gaussmeter) in May 2014. A magnetic induction of $4 \mathrm{kG}$ was measured on the surface of the block (actually the sensor is at a distance of approximately $0.2 \mathrm{~cm}$ because of its isolation). Thus, the magnetic field has decreased by two thirds from originally $12 \mathrm{kG}(1.2 \mathrm{~T})$ when we bought it in January 2013. We were assured by a physicist that this loss over time is completely normal, especially since the neodymium block was stored in a humid environment and thereby began to oxidize. However, even $4 \mathrm{kG}(0.4 \mathrm{~T}=400,000 \mu \mathrm{T})$ are much more than the Earth's magnetic field (around $4.5 \mu \mathrm{T}$ according to Wiltschko \& Wiltschko 1995).

Additionally, we conducted measurements at different distances from the neodymium block, which are plotted in ESM Figure 1 to illustrate the attenuation of the magnetic field (together with the coefficient of determination). At $2 \mathrm{~cm}$ (i.e. the minimum distance of the neodymium block and the border of the barrel; see ESM Figure 2), a value of $800 \mathrm{G}$ has been measured. At $5 \mathrm{~cm}$ (i.e. the maximum distance of the neodymium block and the border of the barrel; see ESM Figure 2), a value of $170 \mathrm{G}$ has been measured. 
Assuming that the magnetic field was three times stronger when we conducted the experiment, the magnetic field that the dolphins encountered when touching the barrel was approximately $510-2400 \mathrm{G}(0.051-0.240 \mathrm{~T})$. Even when entering the experimental area (i.e. a range of $1.5 \mathrm{~m}$ around the barrel), the experimental magnetic field was approximately still stronger than the geomagnetic field (we measured $0.4 \mathrm{G}$ what corresponds to $40 \mu \mathrm{T}$, but this value was probably higher when we conducted the experiment). Taken together, we are sure that the neodymium block used in our study created a magnetic field with a sufficient strength. 


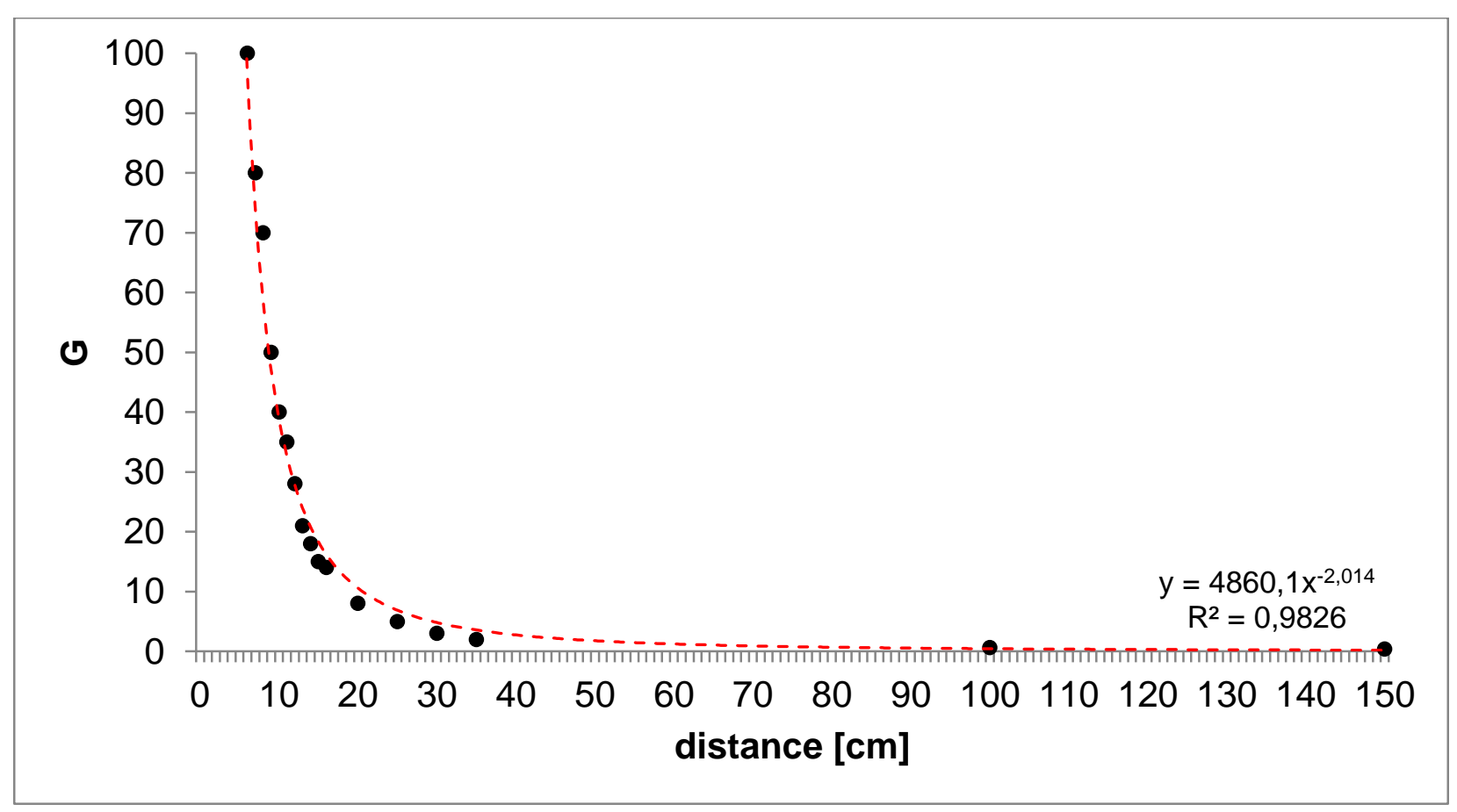

ESM Fig. 1 The magnetic induction [G] of the magnetized neodymium block used as stimulus in this study was measured with a Bell 640 Incremental Gaussmeter at different distances from the block. Note that $1 \mathrm{G}$ corresponds to $100 \mu \mathrm{T}$. On the surface of the block magnetic the magnetic induction was $4 \mathrm{kG}$. Even at a distance of $150 \mathrm{~cm}$ the experimental magnetic field was approximately still stronger $(0.4 \mathrm{G}=40 \mu \mathrm{T})$ than the geomagnetic field (around $4.5 \mu \mathrm{T}$ ). The red dotted line indicates the coefficient of determination. For details see ESM. 


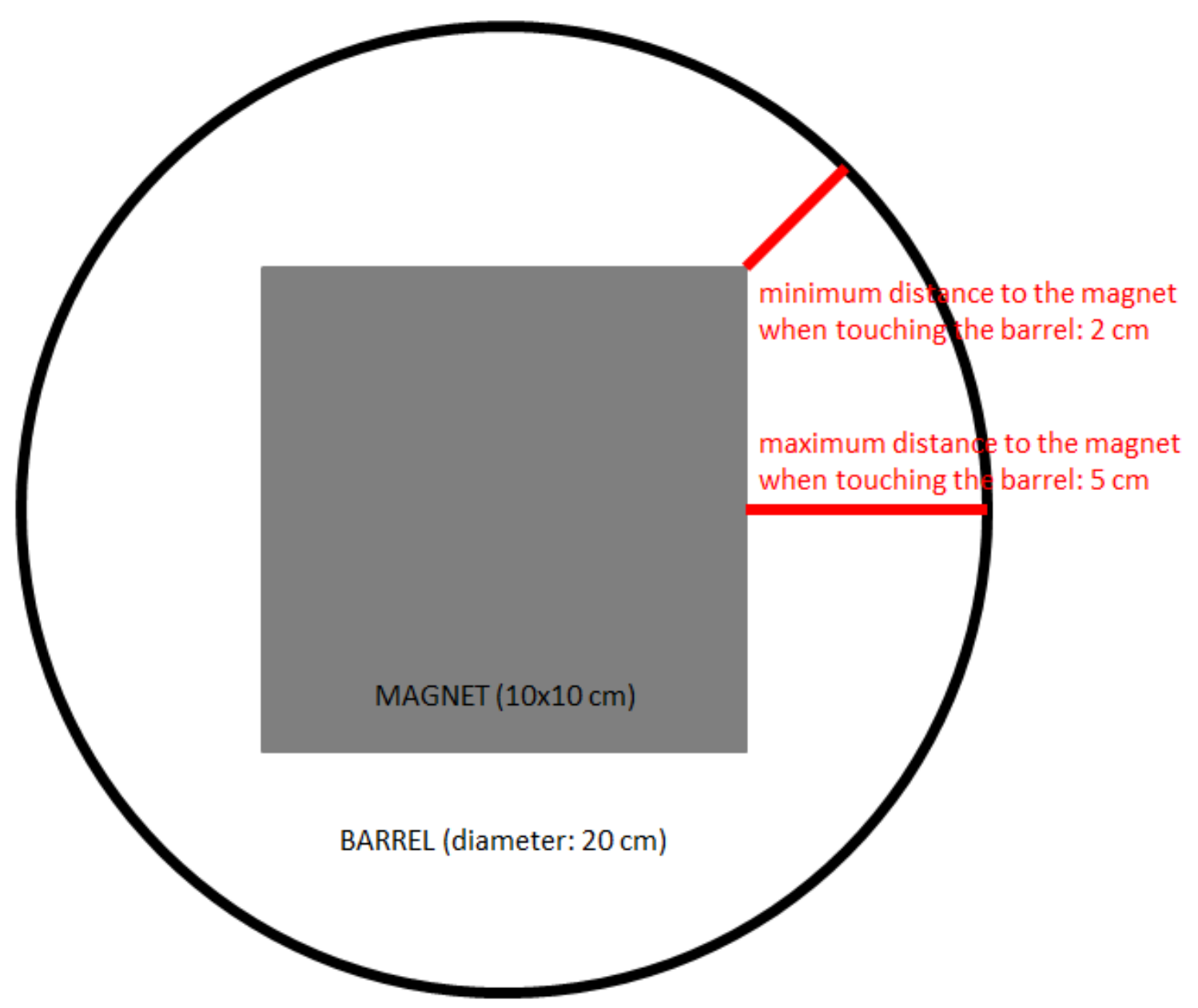

ESM Fig. 2 Sketch of the barrel containing the neodymium block (view from above). When touching the barrel, the distance to the magnet is $2-5 \mathrm{~cm}$ depending on the position. 